http://jmscr.igmpublication.org/home/ ISSN (e)-2347-176x ISSN (p) 2455-0450 crossref DOI: https://dx.doi.org/10.18535/jmscr/v8i1.26

\author{
Journal Of Medical Science And Clinical Research

\title{
A Rare Case of Rifampicin Resistant Primary Sternal Tuberculosis Along with Miliary Tuberculosis of Lung
}

Authors

\section{Manoj Boda ${ }^{1}$, Yasodamma P ${ }^{2}$, Challa Rao GSKP ${ }^{2}$, Komali Dukka ${ }^{3}$, Hruday MohanY ${ }^{4}$}

\begin{abstract}
Skeletal Tuberculosis accounts for 1 to $4 \%$ of the patients with Mycobacterial infection. It occurs due to hematogenous spread and affects all most all the bones. Commonly, Tuberculosis affects the spine, hip, knee, foot bones, elbow and hand bones. Rarely, it affects the shoulder joint. Primary sternal tuberculosis is rare; itsIncidence has been reported to be less than 1\% of TB osteomyelitis cases seen even in endemic countries. As a part of hematogenous spread, it can cause Miliary tuberculosis.
\end{abstract}

Keywords-Miliary TB, Disseminated TB, Sternal tubercular osteomyelitis, Extrapulmonary TB.

\section{Introduction}

Skeletal Tuberculosis accounts for 1 to $4 \%$ of the patients with Mycobacterium infection. It occurs due to hematogenous spread and affects all most al the bones. Commonly, Tuberculosis affects the spine, hip, knee, foot bones, elbow and hand bones. Rarely, it affects the shoulder joint. Primary sternal tuberculosis is rare; its incidence has been reported to be less than $1 \%$ of TB osteomyelitis cases seen even in endemic countries. ${ }^{[1,2]} \mathrm{A}$ thorough literature search of Pub Med database for keywords "primary tuberculosis of sternum" and "primary tubercular osteomyelitis of sternum" yielded 30 and 22 articles, respectively. ${ }^{[3]}$

Disseminated tuberculosis refers to concurrent involvement of at-least two non-contiguoussites of the body. Or, involvement of blood or bone marrow by tuberculosis process. ${ }^{[4,5,6]}$ One form of disseminated TB, which is MiliaryTB, results from massive hematogenous dissemination of tubercle bacilli which results in tiny discrete foci usually the size of millet seeds(1to $2 \mathrm{~mm}$ )more or less uniformly distributed in the lungs and other viscera. ${ }^{[7,8,9]}$
Miliary tuberculosis accounts for less than $2 \%$ of all the cases of $\mathrm{TB}$ and up to $20 \%$ of all extrapulmonary disease.

Rifampicin resistance is a relatively rare event and leads to the selection of mutants that are already resistant to other components of short-course treatment. Therefore Rifampicin resistance is often regarded as a surrogate marker for MDR-TB. ${ }^{[10]}$ RNA polymerase Sub-unit ' $B$ ' is the gene involved in Rifampicin resistance. ${ }^{[11,12,13]}$

We present our experience of an older man with swelling arising from sternum. This type of presentation needs a high amount of suspicion for diagnosis and management.

\section{Case Report}

A 65-year-old male admitted with chief complaints of fever, weight loss, loss of appetite, easy fatigability, edema of both feet for 2 months. He gives the history of swelling over sternum which was small at the onset and gradually reached a size of $7 \mathrm{~cm} \times 4 \mathrm{~cm}$ over a period of 2 months. 


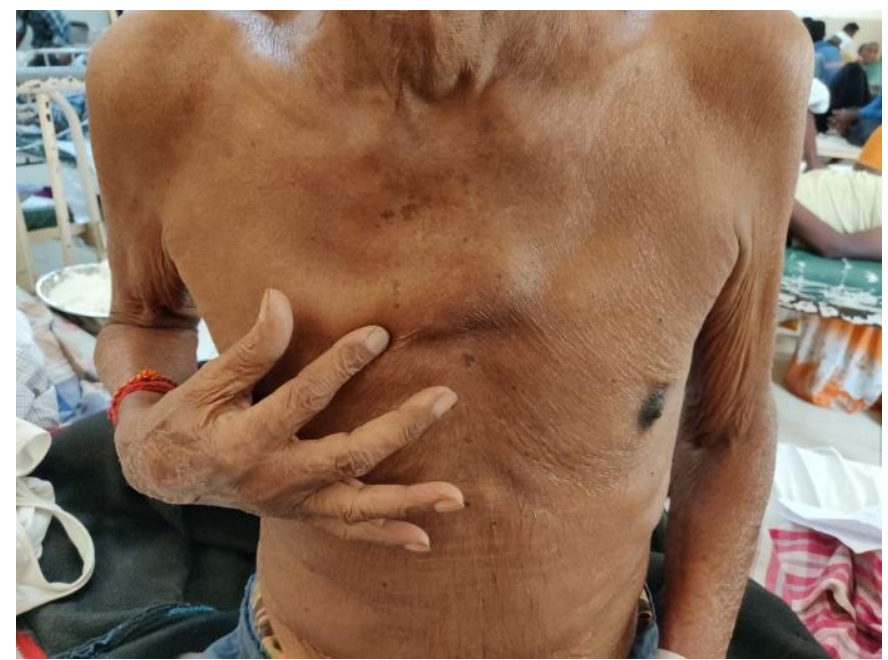

Figure 1-showing swelling over the sternum.

He gives no history of Diabetes, Chronic renal failure/hemodialysis, organ transplantation, HIVAIDS, connective tissue disorders, past history of tuberculosis, household TB contact. He denies usage of corticosteroids, immunosuppressive, immune-modulator drugs. He took over the counter drugs for minor illness from the pharmacy.

On physical examination, he is thin, with BMI 17 $\mathrm{kg} / \mathrm{m}^{2}$. He looked pale, and he had pedal edema. He was worried about having malignancy. He had $7 \mathrm{~cm} \times 4 \mathrm{~cm}$ swelling over the sternum and there were no discharging sinus tracts. His lungs were clear to auscultation. He had no enlarged lymph nodes and the rest of the physical examination was unremarkable.

His laboratory parameters were as follows:

Haemoglobin=9.1g/dl, TWBC $=4100(\mathrm{~N}-50, \quad \mathrm{~L}-44$, M-03,E-03) $\mathrm{RBC}=3.06 \mathrm{Lac} / \mathrm{mm}^{3}$, Haematocrit $=34 \%$, $\mathrm{MCV}=111.2 \mathrm{fl}, \mathrm{MCH}=29.8 \mathrm{pg}, \mathrm{MCHC}=26.8 \mathrm{~g} / \mathrm{dl}$, $\mathrm{RDW}=20.2, \quad$ Platelets $=58000$ cells $/ \mathrm{mm}^{3}$.Peripheral smear examination: RBC-mild Anisopoikilocytosis, microcytic hypochromic RBC, macrocytic cells are also seen, WBC-appear normal in number and morphology, Platelets-appear reduced in number, Hemo-parasites - not seen. Impression — dimorphic anaemia with thrombocytopenia, Reticulocyte count-0.5\%. QBC- negative for Malaria parasite, Widal-negative for Enteric fever, RBS $=125 \mathrm{mg} / \mathrm{dl}$. Serum total proteins $=5.1 \mathrm{mg} / \mathrm{dl}, E S R=49 \mathrm{~mm} / 1^{\text {st }}$ hour.RFT: Serum Creatinine $=0.7 \mathrm{mg} / \mathrm{dl}$, Blood urea $=21 \mathrm{mg} / \mathrm{dl}$. LFT: Total serum bilirubin $=1.0 \mathrm{mg} / \mathrm{dl}, \quad \mathrm{SGOT}=26 \quad \mathrm{IU} / \mathrm{L}, \quad \mathrm{SGPT}=61$ IU/L, ALP=19 IU/L.

Blood Culture - sterile after 72 hours of aerobic incubation for enteric and pyogenic organisms.Urine Microscopy-few pus cells and gram-negative bacilli seen, Urine CultureEscherichia coli isolated.FNAC of the swellingsmears studied show the features suggestive of "CHRONIC GRANULOMATOUS INFLAMMATION” with Caseous necrosis.

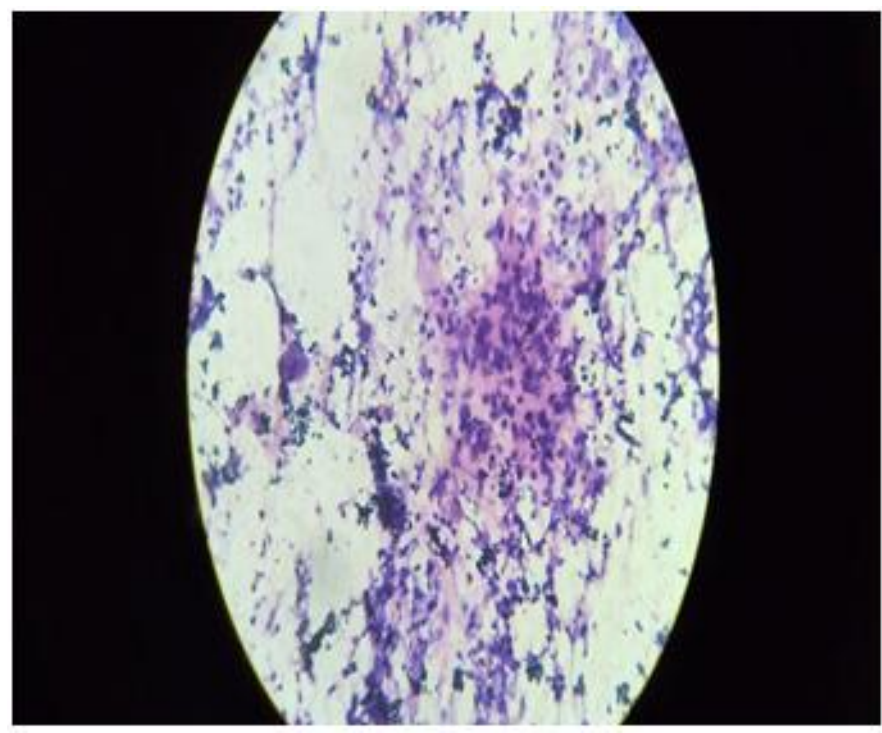

Figure 2-Microscopic image showing epithelioid granuloma.

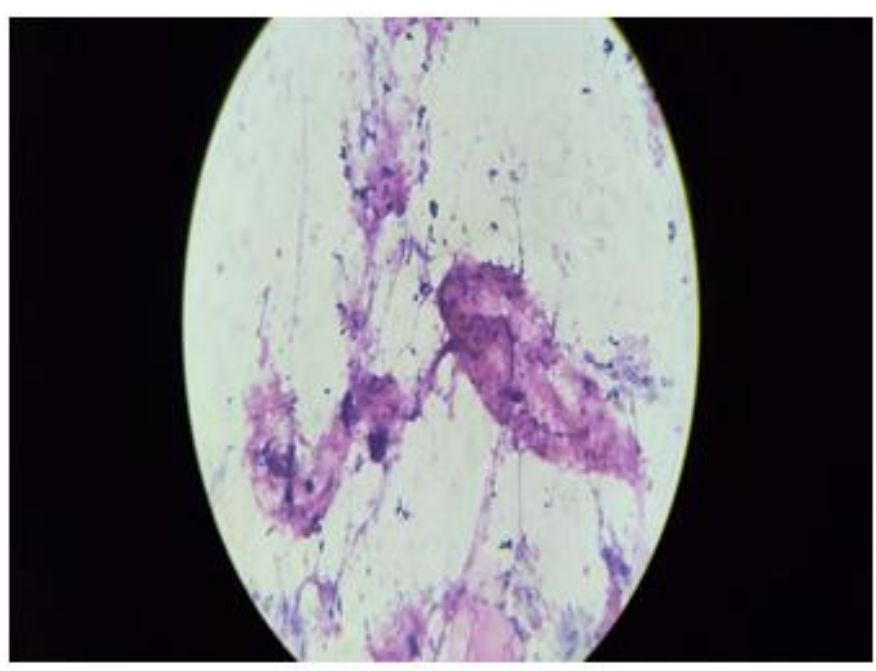

Figure 3-Microscopic image showing caseous necrosis.

CXR--nodular opacities seen bilaterally. HR-CT chest-small multiple miliary nodules noted in both lung fields diffusely-likely tuberculosis, 


\section{JMSCR Vol||08||Issue||01||Page 190-195||January}

mediastinal lymphadenopathy noted, focal destruction of sternum is seen.USG AbdomenSpleenomegaly with altered echotexture.

2D Echocardiography - no regional wall motion abnormality no pericardial effusion, good LV and RV function. Sputum examination-Acid Fast bacilli detected, CB-NAAT-MTB detected and Rifampicin resistance is detected.

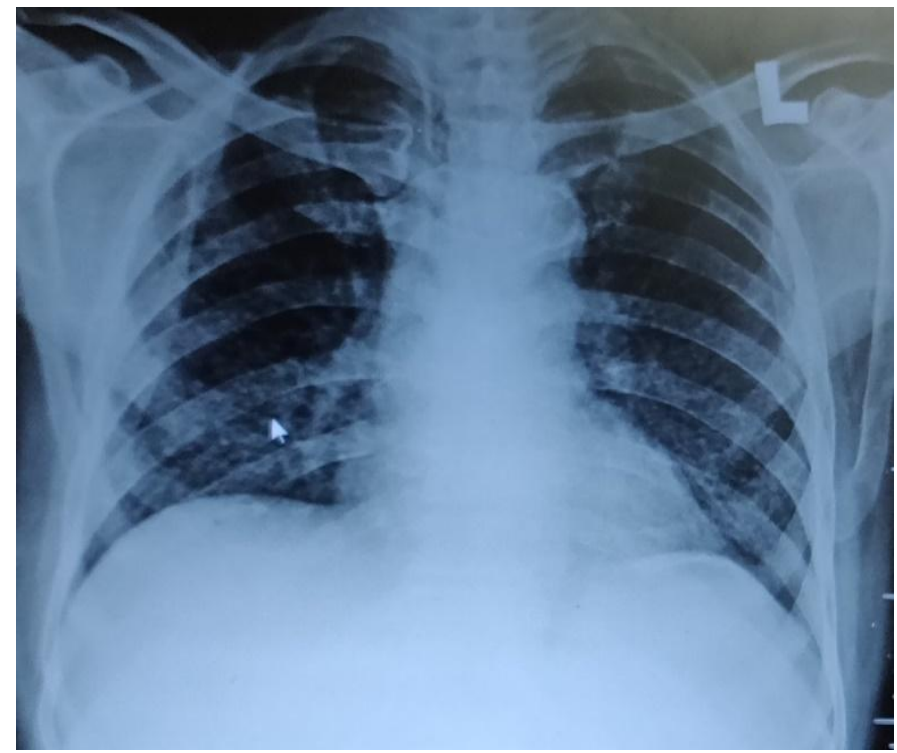

Figure $4-\mathrm{CXR}$ (P/A view) of the patient showing bilateral nodular pattern.



Figure 5-CT chest (saggital view) showing swelling over the sternum. A bulge on the anterior side can be noted .

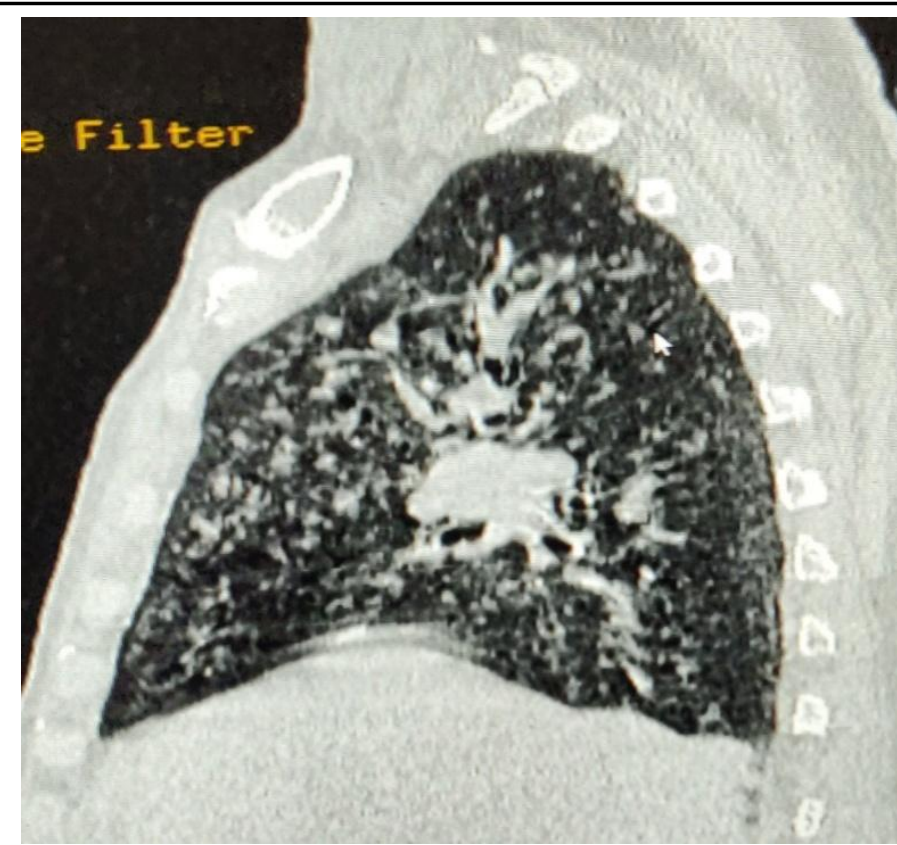

Figure 6-CT chest (saggital section) showing features of miliary tuberculosis.
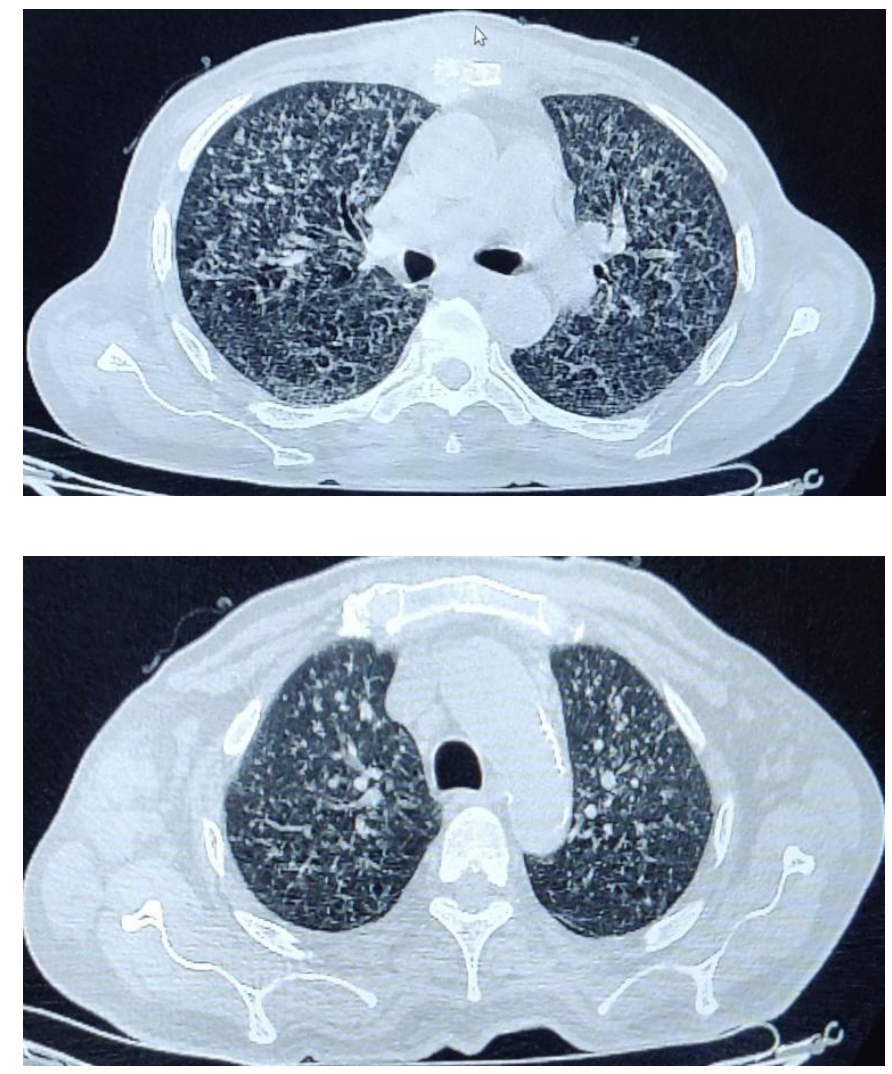

Figures 7 and $8-\mathrm{CT}$ chest(axial sections)showing features of Miliary TB.

\section{Discussion}

Tuberculosis can disseminate to almost every organ after a primary infection or reactivation of latent foci. As per the global TB report 2019, 10 million people fell ill with TB 2018. Adult men were mostly 
affected, which was $57 \%$ of total TB cases in 2018. Eight countries accounted for $2 / 3^{\text {rd }}$ of global disease burden, India-27\%, China-9\%, Indonesia- $8 \%$, Philippines-6\%, Pakistan-6\%, Nigeria-4\%, Bangladesh-4\%, South Africa-3\%. ${ }^{[14]}$

In India total of 21.5lac TB cases were notified, of which $25 \%$ was from the private sector, $89 \%$ of the TB cases were from age group 15 to 69 years. About $2 / 3^{\text {rd }}$ were males. Uttar Pradesh with $17 \%$ of the population of the country, is the most significant contributor to TB cases. $20 \%$ of the disease notifications were from this state.[15] The rate of extra pulmonary TB world-wide has become 10 to $15 \%$. Out of all the extra pulmonary cases, 10 to $25 \%$ have Musculo-skeletal TB with the most commonly affected site being the spine. ${ }^{[14]}$

Approximately 60 to $80 \%$ of the cases of skeletal TB involve the spine or weight-bearing joints while the sternum is involved in about $1 \%$ of cases. It is a rare form of $\mathrm{TB}$, may occur in isolation or association with pleuro-pulmonary or lymph node involvement.

Sternal Mycobacterial infections can be categorized into three varieties-Primary, Secondary, Postoperatively. ${ }^{[16]}$ Tuli and Sinha studied 14 cases of Sternal tuberculosis in a series of 980 cases of Osteo-articular TB. ${ }^{[17]}$ Eyer etal. reviewed 27 articles reporting 32 cases from 1966 to 2013 and found that Primary Sternal tuberculosis was more common in men and occurred at a young age. ${ }^{[18]}$

The reactivation of latent foci formed during hematogenous or lymphatic dissemination of primary $\mathrm{TB}$ is the primary cause of tubercular sternal osteomyelitis. Direct extension from contiguous mediastinal lymph nodes or infection of retro-sternal lymph nodes that erode into the sternum over time are other mechanisms. ${ }^{[16,19.20,21]}$ Thoracic TB disease most commonly involves shafts of ribs or the costovertebral or costochondral junctions, where-as lesions of sternum are more common in the manubrium than the body.

Swelling and pain localized to sternum are the most common presenting symptoms. Constitutional symptoms include malaise, fever, night sweats, and weight loss. In this patient, constitutional symptoms were present and he had swelling over the sternum.Blood investigations are essentially normal in most cases reported apart from raised ESR. Chest radiographs are normal in approximately $70 \%$ of these cases and approximately $40 \%$ have evidence of TB in sites other than sternum. More than $81 \%$ cases of sternal TB have abnormal Tuberculin skin test results.

Plain radiographs are often normal but radiographic techniques like HR-CT and MRI are more valuable. A needle aspiration or excisional biopsy is mandatory for histopathological diagnosis of sternal TB osteomyelitis. The diagnosis is usually confirmed by caseous necrosis and granulomas onhistopathological examination.

The frequency of positive cultures is up to $75 \%$. The newer tests like PCR, Gene Xpert, Nucleic acid amplification can also aid in diagnosis.

A high index of suspicion is required for early diagnosis and prompt treatment that can prevent complications. ATT is the mainstay of treatment with standard four-drug regimen for 6 to 9 months. Surgical drainage of the abscess should be considered only if it does not resolve by aspiration and anti-tubercular therapy.

\section{Conclusion}

Isolated Primary sternal tuberculosis along with miliarytuberculosis, is still rare despite the high prevalence of TB in endemic countries like India. Tubercular involvement of sternum along with other foci can occur with various presentations and can involve any age group. It needs a high index of suspicion. An HR-CT can provide essential clue but confirmation is by culture or histopathological examination remains the mainstay of treatment. Surgical drainage of the abscess should be considered only if it does not resolve by aspiration and anti-tubercular therapy.

\section{References}

1. Tuli SM. Tuberculosis of the spine: a historical review. Clinical Orthopaedics and Related Research (1976-2007). 2007 Jul 1;460:29-38. 
2. Jain AK, Dhammi IK. Tuberculosis of the spine: a review. Clinical Orthopaedics and Related Research (1976-2007). 2007 Jul 1;460:39-49

3. Bains L, Lal P, Chand T, Gautam KK, Beg MY, Kumar P. Isolated primary cold abscess of the sternum: a case report. Journal of medical case reports. 2019 Dec 1;13(1):267.

4. Sharma SK, Mohan A, Gupta R, Kumar A, Gupta AK, Singhal VK, Pande JN. Clinical presentation of tuberculosis in patients with AIDS: an Indian experience. The Indian journal of chest diseases \& allied sciences. 1997;39(4):213-20.

5. Wang JY, Hsueh PR, Wang SK, Jan IS, Lee LN, Liaw YS, Yang PC, Luh KT. Disseminated tuberculosis: a 10-year experience in a medical center. Medicine. 2007 Jan 1;86(1):39-46.

6. Sharma SK, Mohan A, Sharma A, Mitra DK. Miliary tuberculosis: new insights into an old disease. The Lancet infectious diseases. 2005 Jul 1;5(7):415-30.

7. Sahn SA, Neff TA. Miliary tuberculosis.The American journal of medicine. 1974 Apr 1;56(4):495-505.

8. Singla R, Sharma SK, Mohan A, Makharia G, Sreenivas V, Jha B, Kumar S, Sarda P, Singh S. Evaluation of risk factors for antituberculosis treatment induced hepatotoxicity. Indian Journal of Medical Research. 2010 Jul 1;132(1):81-7.

9. Mert A, Ozaras R. A terminological controversy: do disseminated and miliary tuberculosis mean the same?.Respiration. 2005;72(1):113

10. Kumar MM, Shrawan K, Ram D, Kumar GR. Rapid detection of rifampicin resistance in sputum samples using indigenously developed molecular probes and comparison with conventional mic method. Journal of Advance Researches in Biological Sciences. 2013;5(1):19-22.

11. Sreevatsan S, Pan XI, Stockbauer KE, Connell ND, Kreiswirth BN, Whittam TS,
Musser JM. Restricted structural gene polymorphism in the Mycobacterium tuberculosis complex indicates evolutionarily recent global dissemination. Proceedings of the National Academy of Sciences. 1997 Sep 2;94(18):9869-74.

12. Kapur V, Li LL, Iordanescu S, Hamrick MR, Wanger A, Kreiswirth BN, Musser JM. Characterization by automated DNA sequencing of mutations in the gene (rpoB) encoding the RNA polymerase beta subunit in rifampin-resistant Mycobacterium tuberculosis strains from New York City and Texas. Journal of clinical microbiology. 1994 Apr 1;32(4):1095-8.

13. Williams DL, Waguespack C, Eisenach K, Crawford JT, Portaels F, Salfinger M, Nolan CM, Abe C, Sticht-Groh V, Gillis TP. Characterization of rifampin-resistance in pathogenic mycobacteria. Antimicrobial agents and chemotherapy. 1994 Oct 1;38(10):2380-6.

14. World Health Organization. The WHO global task force on TB impact measurement. World Health Organization; 2019.

15. Sachdeva KS, Mase SR. The end TB strategy for India.Indian Journal of Tuberculosis. 2019 Jan 1;66(1):165-6.

16. Yuan SM. Sternal mycobacterial infections. Annals of thoracic medicine. 2016 Apr;11(2):103.

17. Tuli SM, Sinha GP. Skeletal tuberculosis" Unusual" lesions.Indian Journal of Orthopaedics. 1969 Feb 1;3(1):5.

18. Eyer MM, Constantinescu MA, Sendi P. Primary sternal tuberculosis: a case report and review of the literature. Journal of medical microbiology case reports. 2014;1(2).

19. Vasa M, Ohikhuare C, Brickner L. Primary sternal tuberculosis osteomyelitis: A case report and discussion. Canadian Journal of Infectious Diseases and Medical Microbiology. 2009;20(4):e181-4. 
20. Sharma S, Juneja M, Garg A. Primary tubercular osteomyelitis of the sternum. The Indian Journal of Pediatrics. 2005 Aug 1;72(8):709-10.

21. Hongsakul K, Chitrapazt N, Tubtawee T, Jaovisidha S. Primary sternal tuberculosis: a case report and literature review. Southeast Asian Journal of Tropical Medicine and Public Health. 2015;46(1):80. 